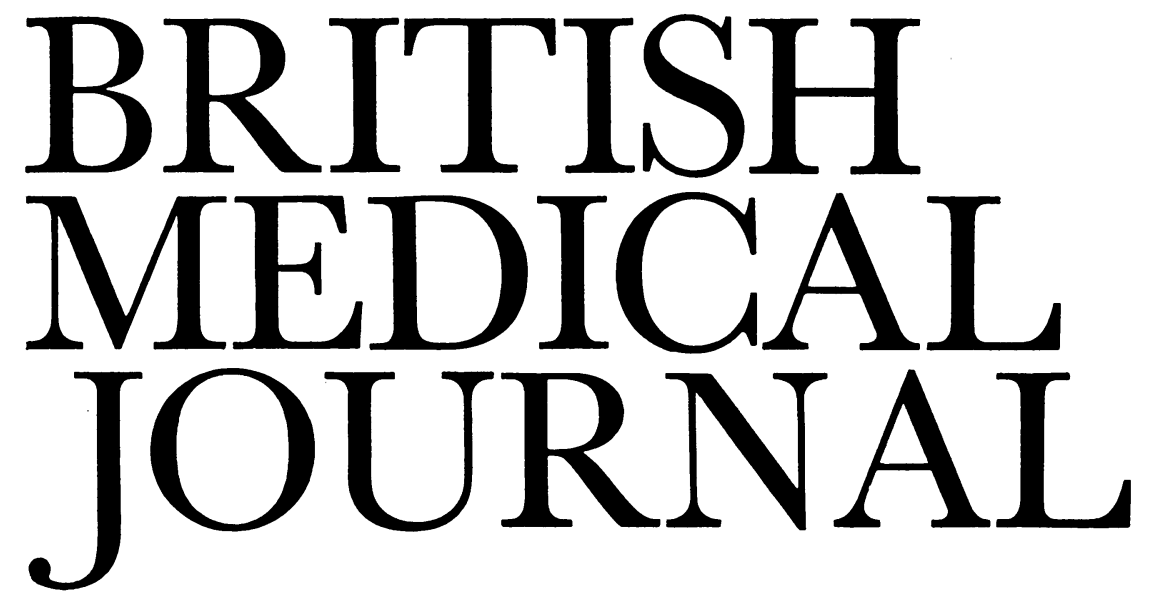

LONDON, SATURDAY 7 JULY 1979

\title{
Doubtful epilepsy in childhood
}

Anyone who deals with people who have had seizures is familiar with the question: Is it epilepsy, doctor? Usually the clinician is clear in his own mind about the answer, and subsequent discussion may centre on the patient's understanding of the word epilepsy and its implications. Occasionally, however, there may be doubt about the nature of the patient's attacks or the doctor may be convinced that, though the attacks in some ways resemble epileptic seizures, they are not epilepsy.

In young children the condition most often confused with epilepsy is breath holding, ${ }^{1}$ which when severe terminates in opisthotonic rigidity and convulsive movements. The invariable feature of these attacks, however, is some precipitant physical or emotional trauma, so that they should be easy to distinguish once a detailed history has been taken. Indeed, the doctor may witness such an attack in clinic if the child is taken from his mother during physical examination. Stephenson ${ }^{2}$ has recently revived a suggestion ${ }^{3}$ that some of these spells (white breath holding) may be due to vagally induced bradycardia or asystole. Breath holding spells are benign but unresponsive to drug treatment. They rarely recur after the age of 6 years.

In the newborn baby convulsions have to be distinguished from "jitteriness," which, once hypoglycaemia and hypocalcaemia have been excluded, is usually of unknown cause and good prognosis. In small premature babies episodes of apnoea and of milk aspiration may cause some confusion. In toddlers episodes of unsteadiness and fearfulness lasting for about 30 seconds, occasionally with vomiting or nystagmus, may be due to the syndrome of benign paroxysmal vertigo. ${ }^{4}$ Older and more intelligent children may describe the feeling of retatory vertigo during the attacks, and the results of caloric testing may be abnormal. The attacks usually cease by the age of 4 or 5 years.

Some seizures have a psychogenic basis-a fact recognised for centuries.5 The differentiation between epilepsy and non-epilepsy may be easy, or it may be impossible. ${ }^{6}$ In his re-examination of Gowers's Borderland of Epilepsy ${ }^{8}$ Williams $^{7}$ emphasised the frequency of a rigid, obsessional, and stoical personality and of hyperventilation in people with neurological symptoms but without organic neurological disease. Finlayson and Lucas ${ }^{9}$ have recently reviewed the findings in 18 children and adolescents seen at the Mayo Clinic between 1970 and 1976, who presented with a diagnosis of epilepsy but were thought to have attacks of entirely emotional origin"pseudoepileptic seizures." These patients commonly showed abnormalities on detailed psychological testing, but the authors warn against too ready a diagnosis of conversion hysteria: anxiety, simple fainting, overbreathing, and malingering are alternative causes of the attacks. Furthermore, true epilepsy and false epilepsy are not mutually exclusive; indeed, pseudoseizures are said to be much more common in epileptic patients, ${ }^{10}$ in whom the possibility of drug intoxication, especially with phenytoin, ${ }^{11}$ should be remembered as a precipitant of "hysterical" seizures.

Experienced observers may be able to make the distinction between true and false epilepsy with some confidence, and a period of inpatient observation may clarify the diagnosis, but often doubt will remain. In centres with facilities for simultaneous split-screen television monitoring of both the patient's behaviour and his electroencephalogram (EEG) the diagnosis may become plain-but, even so, some patients will defy confident diagnosis. Trimble ${ }^{12}$ showed that in patients with generalised epilepsy the serum concentration of prolactin rose to high levels after a fit but that this did not occur in those patients whose attacks were thought to be hysterical. If others confirm this finding it should provide a useful test.

There is a reverse side to the coin. Some patients with epilepsy, especially temporal lobe epilepsy (complex partial seizures), may present with symptoms not immediately suggestive of epilepsy. Thus headaches, ${ }^{13}$ vertigo, ${ }^{14}$ and abdominal pain ${ }^{15}$ may occasionally remain unelucidated until an EEG is performed. Nevertheless, the mainstay of diagnosis in the paroxysmal disorders remains the doctor's ability to take and analyse the patient's history and to assess his symptoms in the context of his psychological makeup.

\footnotetext{
${ }^{1}$ Livingston, S, Comprehensive Management of Epilepsy in Infancy, Childhood, and Adolescence, p 33. Springfield, Charles C Thomas, 1972.

2 Stephenson, J B P, Archives of Disease in Childhood, 1978, 53, 193.

${ }^{3}$ Bridge, E M, Livingston, S, and Tietze, C, fournal of Pediatrics, 1943, 23, 539.

* Chutorian, A M, Developmental Medicine and Child Neurology, 1972, 14, 513.

${ }^{5}$ Glaser, G H, Fournal of Nervous and Mental Disease, 1978, 166, 268.

${ }^{6}$ Betts, T A, in $A$ Textbook of Epilepsy, ed J Laidlaw and A Richens, chap 5, p 160. London and Edinburgh, Churchill Livingstone, 1976.

Williams, D, Brain, 1975, 98, 1 .

${ }^{3}$ Gowers, W R, The Borderland of Epilepsy. London, Churchill, 1907.

9 Finlayson, R E, and Lucas, A R, Mayo Clinic Proceedings, 1979, 54, 83.
} 
${ }^{10}$ Merskey, H, and Buhrich, N A, British fournal of Medical Psychology, $1975,48,359$

11 Neidermeyer, E, et al, Psychiatria Clinica, 1970, 3, 71. (Quoted by Betts, T A, see reference 6 above.)

12 Trimble, M R, British Medical fournal, 1978, 2, 1682.

13 Swaiman, K F, and Frank, Y, Developmental Medicine and Child Neurology, $1978,20,580$.

14 Eviatar, L, and Eviatar, A, Pediatrics, 1977, 59, 833.

15 Papatheophilou, R, Jeavons, P M, and Disney, M E, Developmental Medicine and Child Neurology, 1972, 14, 31.

\section{Units for cardiac surgery}

Cardiac operations that need the use of extracorporeal circulation cost more than most other forms of surgery, largely because of the expense of prosthetic valves and the disposable parts of the extracorporeal circuit. Thus an aortic valve replacement has been calculated to cost $£ 2755$ compared with $£ 1870$ for an oesophagectomy. ${ }^{1}$ Nowadays about $80 \%$ of cardiac operations require an extracorporeal circuit. Such operations demand specialist technicians and an intensive care unit with a high nurse: patient ratio. The proliferation of small units is generally agreed to be undesirable $\mathbf{2}^{\mathbf{3}}$; if it is to perform efficiently the team should function regularly, and any given type of operation should be done reasonably often. For example, Sutherland $e t a l^{4}$ in South Australia assert that the repair of Fallot's tetralogy in children should be confined to paediatric surgical units doing not less than one such operation a month.

From time to time the work done by the 47 cardiac surgical units in Britain and Northern Ireland is reviewed against that background. In 1967 a joint committee of the Royal College of Physicians of London and the Royal College of Surgeons of England issued its first report; in April 1979 the committee reported again. ${ }^{5}$ Its recommendations concern the site, size, work load, and staffing of cardiac centres. The committee recommends that a combined investigation and surgical cardiac centre should be sited at a general hospital (not necessarily a teaching one). A minimum of three cardiac surgeons is envisaged, performing not fewer than 200 open heart operations a year: around 600 operations would be needed where three or four surgeons serve a population of 2.5 to 3.5 million. For diagnostic investigation the committee envisages the equivalent of six whole-time consultant cardiologists, two of whom would have "special expertise in the problems of instrumentation"-a statement which is not further elaborated. The report suggests that the cardiac catheterisation laboratories should be able to take on 40 to 50 investigations a week-a figure that may be intended to include noninvasive procedures such as echocardiography.

The report deals with paediatric surgery separately, calculating that about 1400 infant cardiac catheterisations and 850 infant operations (half under cardiopulmonary bypass) will be required in England and Wales each year. These numbers are too few for management on a strictly regional basis, and the committee has recommended a cut in the number of centres performing this very specialist form of surgery. The ten centres should each be integrated with adult cardiac centres, and be closely associated with children's departments. As to older children, the report forecasts some 3800 catheterisations and 2200 operations (1700 with bypass) annually in England and Wales. These should not all be concentrated in the supraregional infant centres, for this would lead to a decline in services and advice in areas distant from them.
The special position of the London teaching hospitals is acknowledged, but with the admission that there are too many for the population of 10 million which they serve, even allowing for referrals from the provinces. Mergers are therefore recommended, but without naming institutions. These fusions will prove a painful process for hospitals losing their departments.

There can be no disagreement over the report's unequivocal recommendation that cardiac centres should be funded on a national basis; it is unfair that other services should have to compete for money in area or region committees against the high demands of a cardiac centre.

In general the numbers of paediatric and adult valve operations are reasonably predictable. The uncertain element is the future demand for surgery for coronary heart disease. Saphenous vein bypasses must now account for roughly a half of adult heart operations using extracorporeal circulation, and cardiac surgeons would have been underemployed had this development not taken place. Vigilance will be needed to ensure that the expected expansion of numbers in coronary artery surgery is based on careful selection of patients and monitoring of both numbers and results. ${ }^{6}$

1 Morgan, K, Didsbury, F, and Braimbridge, M, Thorax, 1978, 33, 134.

Scannell, J G, et al, Circulation, 1975, 52, A23.

${ }^{3}$ Brewer, L A, Scannell, J G, and Spencer, F C, fournal of Thoracic and Cardiovascular Surgery, 1977, 73, 327.

4 Sutherland, H D, et al, Thorax, 1977, 32, 570

5 Royal College of Physicians and Royal College of Surgeons Committee Second Report on Combined Medical and Surgical Units for Cardiac Surgery. London, Royal College of Physicians of London, 1979. ${ }^{6}$ English, T A, Thorax, 1978, 33, 131

\section{Extracranial-intracranial anastomoses in the treatment of cerebrovascular ischaemia}

Surgical reconstruction of the extracranial arteries supplying the brain is well established for preventing ischaemic stroke. Nevertheless, many patients presenting with such premonitory conditions as transient ischaemic attacks (TIAs) and prolonged reversible ischaemic neurological deficits have more than an uncomplicated stenosis of the internal carotid artery in the neck. At least $15 \%$ have either complete occlusion of the internal carotid artery ${ }^{1}$ or stenosis of the intracranial carotid artery or middle cerebral artery ${ }^{3}$-lesions neither suitable nor accessible for extracranial repair. Recently increasing interest has been shown in treating these patients by bypassing the occluded or stenosed artery by extracranial-to-intracranial anastomosis in the cerebral hemisphere.

The usual technique, developed first by Donaghy ${ }^{4}$ and by Yasargil, ${ }^{5}$ is to anastomose the superficial temporal artery (a branch of the external carotid artery which is usually free of atheroma) to a cortical branch of the middle cerebral artery distal to any block or stenosis. The vessels concerned are between 1 and $1.5 \mathrm{~mm}$ in diameter, and such an anastomosis requires novel surgical skills and instrumentation. High magnification with the operating microscope is essential, as are microsurgical instruments and very fine sutures and needles; and considerable practice is required to perfect the technique. The procedure is, however, now well established and being performed increasingly in specialist centres on patients with TIAs and prolonged reversible deficits and also occasionally 